Post-print: Armengol, Eva ; Dellunde, Pilar; García-Cerdaña, Àngel. A logical study of local and global graded similarities. Applied Artificial Intelligence: An International Journal. Vol. 29, Issue 5, 2015 , p. 424-444. DOI: $\underline{10.1080 / 08839514.2015 .1026657}$

\title{
A Logical Study of Local and Global Graded Similarities
}

\author{
Eva Armengol ${ }^{1}$, Pilar Dellunde ${ }^{1,2}$, Àngel García-Cerdaña ${ }^{1,3, *}$ \\ ${ }^{1}$ Artificial Intelligence Research Institute (IIIA) \\ Spanish National Research Council (CSIC) \\ Campus UAB, 08193 Bellaterra, Catalonia, Spain \\ 2 Department of Philosophy \\ Universitat Autonoma de Barcelona \\ Campus UAB, 08193 Bellaterra, Catalonia, Spain \\ ${ }^{3}$ Department of Information and Communication Technologies \\ Universitat Pompeu Fabra \\ Tànger 122-140, 08018 Barcelona, Catalonia, Spain
}

Abstract. In this paper we study the relationship between global and local similarities in the graded framework of Fuzzy Class Theory (FCT) in which already exists a graded notion of similarity. In FCT we can express the fact that a fuzzy relation is reflexive, symmetric or transitive up to a certain degree, and similarity is defined as a first-order sentence which is the fusion of three sentences corresponding to the graded notions of reflexivity, symmetry and transitivity. This allows to speak in a natural way of the degree of similarity of a relation. We consider global similarities defined from local similarities using t-norms as aggregation operators and we obtain some results in the framework of FCT that adequately interpreted allow us to say that, when we take a t-norm as aggregation operator the properties of reflexivity, symmetry and transitivity of fuzzy binary relations at the global level inherit the properties of the fuzzy binary relations at the local level when we fusion them, and that the global similarity is a congruence if some of the local similarities are congruences.

\section{Introduction}

This paper is an extended version of Armengol et al. [in press], where we began the logical logical study of the similarity relation between objects represented as attributevalue pairs. Ruspini [1991] suggests that the degree of similarity between two objects $\mathrm{A}$ and $\mathrm{B}$ may be regarded as the degree of truth of the vague proposition "A is similar to B". Thus, similarity among objects can be seen as a phenomenon essentially fuzzy.

\footnotetext{
${ }^{*}$ Corresponding author
} 
The notion of similarity in Fuzzy Sets Theory was introduced by Zadeh [1971] as a generalization of the notion of equivalence relation (see Recasens [2011] for a historical overview on the notion of t-norm based similarity). As Zadeh pointed out, one of the possible semantics of fuzzy sets is in terms of similarity. Indeed, the membership degree of an object to a fuzzy set can be seen as the degree of resemblance between this object and prototypes of the fuzzy set. From a logical point of view, Hájek [1998] studies similarities and congruences in fuzzy predicate logics and proposes axioms for them in the context of the logic BL $\forall$.

It is worth stressing that the common approach to similarity between objects is to define it by means the dual of a distance measure. This implies that objects are described geometrically. At this point we want to go beyond this idea integrating more general ideas of similarity as those set by the cognitive and mathematical psychologist Amos Tversky (1937-1996), who argues that often objects are not described geometrically but symbolically. In fact, he shows situations in which similarities do not satisfy the mathematical notions of (dual) metrics (see Tversky [1977]). In these cases, he proposes to define similarity through the comparison of the features that describe these objects. At this point, following these ideas, to assess the similarity between two objects by comparing their features, we need:

- To assess how similar are both objects in each feature, and then to aggregate these similarities.

- To consider weaker notions of similarity in which reflexivity, symmetry or transitivity does not necessarily hold, or hold only up to some degree.

To illustrate this idea, let us consider the following table describing the mutual feelings between three persons by a degree between 0 and 1 .

\begin{tabular}{|c|c|c|c|}
\hline feelings & John & Mary & Peter \\
\hline John & 1 & 0.6 & 0.2 \\
Mary & 0.3 & 0.8 & 0.7 \\
Peter & 0.5 & 0.9 & 0.4 \\
\hline
\end{tabular}

Such relation does not satisfy these three properties in degree 1 since: a) feelings is not reflexive because feelings(Mary, Mary) $=0.8=1 ; b$ ) feelings is not symmetric since Mary loves John with degree 0.3 whereas John loves Mary with degree 0.6; and c) feelings is not transitive since feelings(John, Mary) $=0.6$, feelings(Mary, Peter) $=$ 0.7 , but feelings $($ John, Peter $)=0.2$

In order to deal with a notion of similarity integrating these ideas, we study the relationship between global and local similarities in the graded framework of Fuzzy Class Theory (FCT) in which already exists a graded notion of similarity. FCT, introduced in [Běhounek and Cintula, 2005], is a part of Mathematical Fuzzy Logic [Hájek, 1998, Běhounek et al., 2011] devoted to the axiomatization of the notion of fuzzy set. This formalism serves as foundation of a large part of fuzzy mathematics. In particular, fuzzy relations like fuzzy orders and similarities can be studied in this graded framework. For instance, in FCT we can express the fact that a fuzzy relation is reflexive, symmetric or transitive up to a certain degree. Thus, these properties are expressed by means of first-order sentences. For instance, the degree up to which the relation $\mathrm{R}$ is reflexive is the truth-value of the sentence $\operatorname{Refl}(\mathrm{R})=\forall \mathrm{xRxx}$. Then, similarity is defined as a first-order sentence which is the fusion of three sentences corresponding to the graded notions of reflexivity, symmetry and transitivity. This allows to speak in a natural way of the degree of similarity of a relation. 
Global similarities between objects can be defined as the aggregation of local similarities (defined between values of the object's attributes). As references of the subject of aggregation operations see [Detyniecki, 2001, Mayor and Mesiar, 2002, Dubois and Prade, 2004]. Important aggregation operators are t-norms and t-conorms [Klement et al., 2000]. Using these kinds of operations we can define global similarities in a multiplicative way as "fusion" of local similarities, or in an additive way as residuated sum of such local similarities. In this paper we consider global similarities defined from local similarities using t-norms. In addition we study the relationship between the degree of properties such as reflexivity, symmetry and transitivity of global similarities and the degree of the same properties in local similarities. We obtain some results in the framework of FCT that adequately interpreted allow us to say that, when we take a t-norm as aggregation operator:

- the properties of reflexivity, symmetry and transitivity of fuzzy binary relations at the global level inherit the properties of the fuzzy binary relations at the local level when we fusion them (Proposition 1),

- the global similarity is a congruence if some of the local similarities are congruences (Proposition 2).

The paper is organized as follows. In Section 2 we introduce some notions concerning similarity and the basics of FCT. In Section 3 we present our main logical results. Finally there is a section devoted to conclusions and future work.

\section{Preliminaries}

A triangular norm (or t-norm) [Klement et al., 2000] is a binary operation defined on the real interval $[0,1]$ satisfying the following properties: associative, commutative, non decreasing in both arguments, and having 1 as unit element. Given the usual order in $[0,1]$, a left-continuous t-norm $*$ is characterized by the existence of a unique operation $\rightarrow_{*}$ satisfying, for all $\mathrm{x}, \mathrm{y}, \mathrm{z} \in[0,1]$, the condition

$$
\mathrm{x} * \mathrm{z} \leq \mathrm{y} \Leftrightarrow \mathrm{z} \leq \mathrm{x} \rightarrow \text { * } \mathrm{y} .
$$

This operation is called the residuum of the t-norm and it satisfies

$$
\mathrm{x} \rightarrow_{\star} \mathrm{y}:=\max \{\mathrm{z}: \mathrm{x} * \mathrm{z} \leq \mathrm{y}\} .
$$

A continuous t-norm is a left-continuos t-norm satisfying the so-called divisibility condition: for all $\mathrm{x}, \mathrm{y} \in[0,1], \min \{\mathrm{x}, \mathrm{y}\}=\mathrm{x} *\left(\mathrm{x} \rightarrow_{\star} \mathrm{y}\right)$. A prominent left-continuous

\begin{tabular}{|c|c|}
\hline * & NM \\
\hline$x * y$ & $\begin{array}{ll}0, & \text { if } \mathrm{x} \leq 1-\mathrm{y} \\
\mathrm{y}, & \text { otherwise }\end{array}$ \\
\hline$x \rightarrow \star y$ & $\neg \mathrm{x} \vee \mathrm{y}$ \\
\hline
\end{tabular}

Table 1: The left-continuous t-norm Minimum Nilpotent (NM) and its residuum. 
Table 2: The three main continuous t-norms and their residua.

\begin{tabular}{|c|c|c|c|}
\hline * & Minimum (Gödel) & Product & Łukasiewicz \\
\hline$x * y$ & $\min (x, y)$ & $x \cdot y$ & $\max (0, x+y-1)$ \\
\hline $\mathrm{x} \rightarrow{ }_{*} \mathrm{y}$ & $\begin{array}{ll}1, & \text { if } \mathrm{x} \leq \mathrm{y} \\
\mathrm{y}, & \text { otherwise }\end{array}$ & $\begin{array}{ll}1, & \text { if } x \leq y \\
y / x, & \text { otherwise }\end{array}$ & $\min (1,1-x+y)$ \\
\hline
\end{tabular}

t-norm that is not continuous is the Nilpotent Minimum (see Table 1). The three basic continuous t-norms are the Minimum, Product and Łukasiewicz (see Table 2). These are the basic ones since any continuous t-norm can be expressed as an ordinal sum of copies of them [Mostert and Shields, 1957, Ling, 1965].

Given a t-norm *, a similarity relation [Ruspini, 1991, Recasens, 2011] defined on a universe $\mathrm{U}$ is a function

$$
\begin{aligned}
& \text { s : } \quad \mathrm{U} \times \mathrm{U} \rightarrow[0,1] \\
& \text { hx, yi } 7 \rightarrow \text { s(x, } \\
& \text { y) }
\end{aligned}
$$

such that, for every $x, y, z \in U$, the following hold:

1. $\mathrm{s}(\mathrm{x}, \mathrm{x})=1$,

(Reflexivity)

2. $s(x, y)=s(y, x)$

(Symmetry)

3. $\mathrm{s}(\mathrm{x}, \mathrm{y}) * \mathrm{~s}(\mathrm{y}, \mathrm{z}) \leq \mathrm{s}(\mathrm{x}, \mathrm{z})$.

(Transitivity)

Observe the duality of this notion with the one of normalized distance. The property

$$
\mathrm{d}(\mathrm{x}, \mathrm{y}) \oplus \mathrm{d}(\mathrm{y}, \mathrm{z}) \geq \mathrm{d}(\mathrm{x}, \mathrm{z}),
$$

being $\oplus$ a tconorm, is a generalization of the triangular inequality. Hájek [1998] studies similarities and congruences in fuzzy predicate logics and proposes the following similarity axioms ${ }^{1}$ :

$$
\begin{array}{ll}
\text { (S1) } \quad(\forall x) x \approx x & \text { (Reflexivity) } \\
\text { (S2) } \quad(\forall x, y)(x \approx y \rightarrow y \approx x) & \text { (Symmetry) } \\
\text { (S3) } \quad(\forall x, y, z)(x \approx y \& y \approx z \rightarrow x \approx z) & \text { (Transitivity) }
\end{array}
$$

and a congruence axiom for every $\mathrm{n}$-ary predicate $\mathrm{P}$ in the language: $\left(\forall \mathrm{x}_{1}, \ldots, \mathrm{x}_{\mathrm{n}}, \mathrm{y}_{1}, \ldots, \mathrm{y}_{\mathrm{n}}\right)\left(\mathrm{x}_{1} \approx \mathrm{y}_{1} \& \cdots \& \mathrm{x}_{\mathrm{n}} \approx \mathrm{y}_{\mathrm{n}} \rightarrow\left(\mathrm{P}_{1}, \ldots, \mathrm{x}_{\mathrm{n}} \leftrightarrow \mathrm{P}_{1}, \ldots \mathrm{y}_{\mathrm{n}}\right)\right)$.

Fuzzy Class Theory (FCT) was introduced in [Běhounek and Cintula, 2005] with the aim to axiomatize the notion of fuzzy set, and it is based on the logic $Ł \Pi \forall$. Later in [Běhounek et al., 2008] the FCT was based in the more general setting of the logic $\mathrm{MTL}_{\Delta} \forall$. In such paper, Běhounek et al. studied fuzzy relations in the context of FCT, generalizing existing crisp results on fuzzy relations to the graded framework. The algebra of truth values for formulas is the standard $\mathrm{MTL}_{\Delta}$-chain over the real unit interval $[0,1]$.

Let us recall the axiomatization of the logic $\mathrm{MTL}_{\Delta} \forall$ (for a presentation of this logic see [Běhounek et al., 2008, Apendix A]). The primitive connectives are $\&, \rightarrow, \wedge, \Delta$, and $\overline{0}$. Negation $\neg$ is defined by $\neg \phi:=\phi \rightarrow \overline{0}$.

\footnotetext{
${ }^{1}$ In order to economize parenthesis we will consider $\rightarrow$ the least binding connective.
} 
Axioms:

(MTL1)

(MTL2)

(MTL3)

(MTL4)

(MTL5)

(MTL6)

(MTL7a)

(MTL7b)

(MTL8)

(MTL9)

$(\Delta 1)$

$(\Delta 2)$

$(\Delta 3)$

$(\Delta 4)$

$(\Delta 5)$

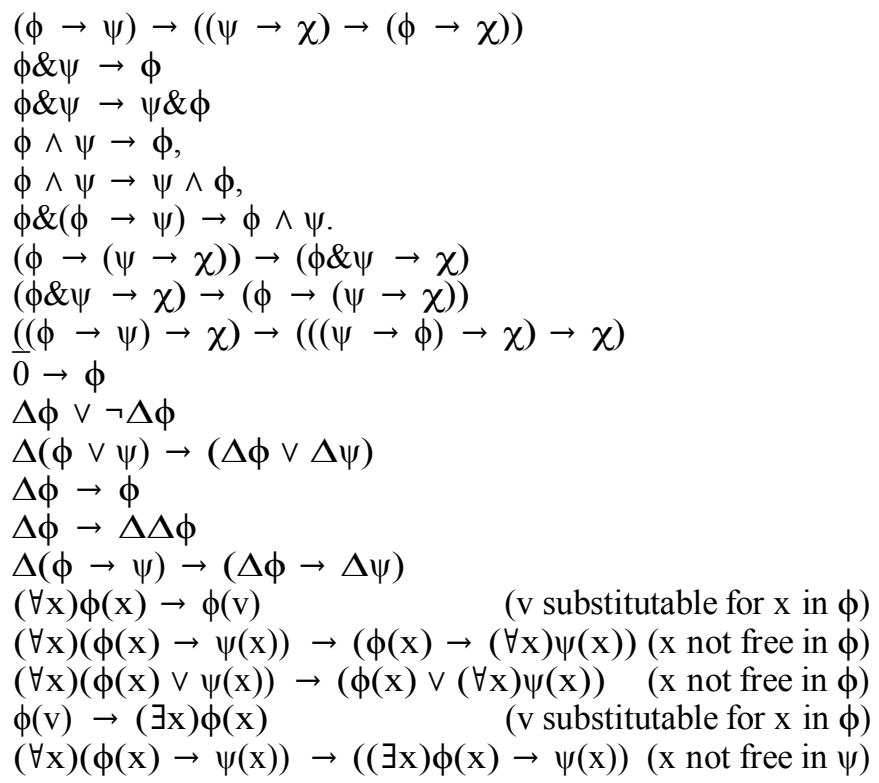

Rules:

Modus ponens

Generalization

$\Delta$-Necessitation

$$
\begin{aligned}
& \phi, \phi \rightarrow \psi \\
& \phi-(\forall x) \phi(x) \\
& \phi-\Delta \phi
\end{aligned}
$$

A standard $\mathrm{MTL}_{\Delta}$-chain is an algebra $\mathrm{T}=\mathrm{h}[0,1]_{\mathrm{R}}, \max , \min ,{ }_{*}, \rightarrow_{\star}, \delta, 0,1 \mathbf{i}$, where $*$ is any left-continuous tnorm, $\rightarrow_{*}$ is the residuum of $*$, and $\delta$ is the operation defined by $\delta 1=1$, and $\delta \mathrm{x}=0$ if $\mathrm{x}=1$.

Let $\mathrm{hP}, \mathrm{F} \mathbf{i}$ a first-order signature (predicate symbols and functional symbols). Given a $\mathrm{T}$ be a standard $\mathrm{MTL}_{\Delta}$-chain, a $\mathrm{T}$-structure for the signature $\mathrm{hP}, \mathrm{F} \mathbf{i}$ is a tuple

$$
\mathrm{M}=h \mathrm{M},\left\{\mathrm{P}^{\mathrm{M}}: \mathrm{P} \in \mathrm{P}\right\},\left\{\mathrm{f}^{\mathrm{M}}: \mathrm{f} \in \mathrm{F}\right\} \mathbf{i}
$$

where

1) $\mathrm{M}$ is a non-empty set (the universe of the structure);

2) for each $k$-ary $P \in P, \quad P^{M}: M^{k} \rightarrow[0,1], \quad$ if $k \geq 1$,

3) for each k-ary $f \in F, \quad \mathbf{f}^{\mathrm{M}}: \mathrm{M}^{\mathrm{k}} \rightarrow \mathrm{M}, \quad$ if $\mathrm{k} \geq 1$,

Given an assignation $v$ of the variables in $M$, the value of a term $t$ in $M$ is defined by:

$$
\mathrm{ktk}_{\mathrm{M}, \mathrm{v}}=\begin{array}{cl}
\square \quad & \text { if } \mathrm{t}=\mathrm{x}, \\
\left.\mathrm{a}^{\mathrm{M}}\right), & \text { if } \mathrm{t} \text { is a constant } \mathrm{a}, \\
\mathrm{f}^{\mathrm{M}}\left(\mathrm{kt}_{1} \mathrm{k}_{\mathrm{M}, \mathrm{v}}, \ldots \mathrm{kt}_{\mathrm{k}} \mathrm{k}_{\mathrm{M}, \mathrm{v}}\right), & \text { if } \mathrm{t}=\mathbf{f}\left(\mathrm{t}_{1}, \ldots, \mathrm{t}_{\mathrm{k}}\right) .
\end{array}
$$

Let $\mathrm{v}$ be an M-assignation such that $\mathrm{v}\left(\mathrm{x}_{1}\right)=\mathrm{b}_{1}, \ldots, \mathrm{v}\left(\mathrm{x}_{\mathrm{n}}\right)=\mathrm{b}_{\mathrm{n}}$. The truth value over the chain $\mathrm{T}$ of a formula for $\mathrm{v}$ is a value in $[0,1]$ inductively defined as follows: 


$$
\begin{aligned}
& \mathrm{kP}\left(\mathrm{t}_{1}, \ldots, \mathrm{t}_{\mathrm{k}}\right) \mathrm{k}_{\mathrm{M}, \mathrm{v}}=\mathrm{P}^{\mathrm{M}}\left(\mathrm{kt}_{1} \mathrm{k}_{\mathrm{M}, \mathrm{v}}, \ldots, \mathrm{kt}_{\mathrm{k}} \mathrm{k}_{\mathrm{M}, \mathrm{v}}\right)
\end{aligned}
$$

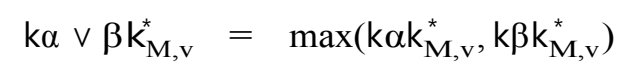

$$
\begin{aligned}
& \mathrm{k} \alpha \wedge \beta \mathrm{k}_{\mathrm{M}, \mathrm{v}}^{*}=\min \left(k \alpha k_{\mathrm{M}, \mathrm{v}}^{*}, k \beta \mathrm{k}_{\mathrm{M}, \mathrm{v}}^{*}\right) \\
& \mathrm{k} \alpha \& \beta \mathrm{k}_{\mathrm{M}, \mathrm{v}}^{*}=k \alpha \mathrm{k}_{\mathrm{M}, \mathrm{v}}^{*} * \mathrm{k} \beta \mathrm{k}_{\mathrm{M}, \mathrm{v}}^{*} \\
& k \alpha \rightarrow \beta k_{M, v}^{*}=k \alpha k_{M, v}^{*} \rightarrow_{\star} k \beta k_{M, v}^{*} \\
& \mathrm{k} \Delta \alpha \mathrm{k}_{\mathrm{M}, \mathrm{v}}^{*}=\delta \mathrm{k} \alpha \mathrm{k}_{\mathrm{M}, \mathrm{v}}^{*} \\
& \mathrm{k}(\forall \mathrm{x}) \alpha\left(\mathrm{x}, \mathrm{x}_{1}, \ldots, \mathrm{x}_{\mathrm{n}}\right) \mathrm{k}_{\mathrm{M}, \mathrm{v}}^{*}=\inf \left\{\mathrm{k} \alpha\left(\mathrm{a}, \mathrm{b}_{1}, \ldots, \mathrm{b}_{\mathrm{n}}\right) \mathrm{k}_{\mathrm{M}}^{*}: \mathrm{a} \in \mathrm{M}\right\} \\
& \mathrm{k}(\exists \mathrm{x}) \alpha\left(\mathrm{x}, \mathrm{x}_{1}, \ldots, \mathrm{x}_{\mathrm{n}}\right) \mathrm{k}_{\mathrm{M}, \mathrm{v}}^{*}=\sup \left\{\mathrm{k} \alpha\left(\mathrm{a}, \mathrm{b}_{1}, \ldots, \mathrm{b}_{\mathrm{n}}\right) \mathrm{k}_{\mathrm{M}}^{*}: \mathrm{a} \in \mathrm{M}\right\}
\end{aligned}
$$

A formula $\phi$ is valid in an $\mathrm{T}$-structure $\mathrm{M}$ (denoted as $\mathrm{M} \models \phi$ ) if $k \phi \mathrm{k}_{\mathrm{M}, \mathrm{v}}^{*}=1$ for every assignation v. A T -structure $\mathrm{M}$ is a L-model of a theory $\Gamma$ if $\mathrm{M} \models \phi$ for each $\phi \in \Gamma$.

Theorem 1 (Completeness Theorem) Let $\Gamma$ be a theory and $\phi$ be a formula. The following conditions are equivalent:

1. $\Gamma^{-} \phi$.

2. $\mathrm{M} F \phi$ for each standard $\mathrm{MTL}_{\Delta}$-chain $\mathrm{T}$ and each $\mathrm{T}$-model $\mathrm{M}$ of $\Gamma$.

Fuzzy Class Theory over $\mathrm{MTL}_{\Delta}$ is a theory over the multi-sorted first-order logic $\mathrm{MTL}_{\Delta} \forall$ with crisp equality. It has sorts of individuals of order 0 (atomic objects) $\mathrm{a}, \mathrm{b}, \mathrm{c}, \mathrm{x}, \mathrm{y}, \mathrm{z}, \ldots$; individuals of the first-order (fuzzy classes) $\mathrm{A}, \mathrm{B}, \mathrm{X}, \mathrm{Y}, \ldots$; individuals of the second-order (fuzzy classes of fuzzy classes) $A, B, X, Y, \ldots$. For every variable $\mathrm{x}$ of any order $\mathrm{n}$ and for every formula $\phi$ there is a class term $\{\mathrm{x} \mid \phi\}$ of order $n+1$. Besides the logical predicate of identity, the only primitive predicate is the membership predicate $\in$ between successive sorts. For variables of all orders, the axioms for $\in$ are:

$(\in 1) \quad \mathrm{y} \in\{\mathrm{x} \mid \phi(\mathrm{x})\} \leftrightarrow \phi(\mathrm{y})$, for every formula $\phi, \quad$ (Comprehension Axioms)

$(\in 2) \quad(\forall \mathrm{x}) \Delta(\mathrm{x} \in \mathrm{A} \leftrightarrow \mathrm{x} \in \mathrm{B}) \rightarrow \mathrm{A}=\mathrm{B} . \quad$ (Extensionality)

The basic properties of fuzzy relations are defined as sentences as follows:

Definition 1 Let $\mathrm{R}$ be a binary predicate symbol.

Reflexivity: $\operatorname{Refl}(\mathrm{R}) \equiv_{\mathrm{df}}(\forall \mathrm{x}) \mathrm{Rxx}$

Symmetry: $\quad \operatorname{Sym}(\mathrm{R}) \equiv_{\mathrm{df}}(\forall \mathrm{x}, \mathrm{y})(\mathrm{Rxy} \rightarrow \mathrm{Ryx})$

Transitivity: $\quad \operatorname{Trans}(\mathrm{R}) \equiv_{\mathrm{df}}(\forall \mathrm{x}, \mathrm{y}, \mathrm{z})(\mathrm{Rxy} \& \mathrm{Ryz} \rightarrow \mathrm{Rxz})$

Example 1 Let $R_{1}, R_{2}$ and $R_{3}$ be fuzzy relations on the set $U=\{u, v\}$ defined as follows:

$$
\mathrm{R}_{1}=\begin{array}{ccccc}
1 & 1 \\
0.5 & 0.7 & \mathrm{R}_{2}= & 0.7 & 1 \\
1 & 0.2
\end{array} \quad \mathrm{R}_{3}=\begin{array}{ccc}
1 & 0.3 \\
0.9 & 1
\end{array}
$$

The elements of the matrices above correspond to the following distribution of values:

$$
R_{i}=\begin{array}{ll}
R_{i} u u & R_{i} u v \\
R_{i} v u & R_{i} v v
\end{array}
$$


In such situation, the truth value of $\operatorname{Refl}\left(\mathrm{R}_{\mathbf{i}}\right)$ is obtained in the following way:

$$
\left\|\operatorname{Refl}\left(\mathrm{R}_{\mathrm{i}}\right)\right\|=\inf \left\{\mathrm{R}_{\mathrm{i}} \mathrm{uu}, \mathrm{R}_{\mathrm{i}} \mathrm{vv}\right\} .
$$

Thus, $\left\|\operatorname{Refl}\left(\mathrm{R}_{1}\right)\right\|=0.7,\left\|\operatorname{Refl}\left(\mathrm{R}_{2}\right)\right\|=0.2$, and $\left\|\operatorname{Refl}\left(\mathrm{R}_{3}\right)\right\|=1$. The truth value of $\operatorname{Sym}\left(R_{i}\right)$ is obtained as follows:

$$
\left\|\operatorname{Sym}\left(R_{i}\right)\right\|=\inf \left\{R_{i} u u \rightarrow_{*} R_{i} u u, R_{i} u v \rightarrow_{*} R_{i} v u, R_{i} v u \rightarrow_{*} R_{i} u v, R_{i} v v \rightarrow_{*} R_{i} v v\right\}
$$

To calculate this truth value we need to take a t-norm. Let us suppose we choose the minimum t-norm. According to Table 2 the residuum of the minimum t-norm is 1 when $\mathrm{x} \leq \mathrm{y}$, and $\mathrm{y}$ otherwise. Thus, for instance, $\mathrm{R}_{1} \mathrm{uv} \rightarrow_{\star} \mathrm{R}_{1} \mathrm{vu}=1 \rightarrow_{\star} 0.5=0.5$. Proceeding similarly with all the terms and for each $R_{i}$ we obtain:

$$
\begin{aligned}
& \left\|\operatorname{Sym}\left(R_{1}\right)\right\|=\inf \{1,0.5,1,1\}=0.5, \\
& \left\|\operatorname{Sym}\left(R_{2}\right)\right\|=\inf \{0.7,1,1,0.2\}=1, \\
& \left\|\operatorname{Sym}\left(R_{3}\right)\right\|=\inf \{1,1,0.3,1\}=0.3 .
\end{aligned}
$$

If we take the t-norm of Łukasiewicz, the symmetry degrees corresponding to $\operatorname{Sym}\left(R_{\mathbf{i}}\right)$ are the following: $\left\|\operatorname{Sym}\left(R_{1}\right)\right\|=0.5,\left\|\operatorname{Sym}\left(R_{2}\right)\right\|=1$, and $\left\|\operatorname{Sym}\left(R_{3}\right)\right\|=0.6$. Finally, the truth value of $\operatorname{Trans}\left(\mathrm{R}_{\mathbf{i}}\right)$ is obtained as follows:

$$
\begin{aligned}
\left\|\operatorname{Trans}\left(R_{i}\right)\right\|=\inf \{ & R_{i} u u * R_{i} u u \rightarrow \star R_{i} u u, R_{i} u u * R_{i} u v \rightarrow_{\star} R_{i} u v, \\
& R_{i} u v * R_{i} v u \rightarrow{ }_{i} u v, R_{i} u v * R_{i} v v \rightarrow_{\star} R_{i} v v, \\
& R_{i} v v * R_{i} v v \rightarrow_{\star} R_{i} v v, R_{i} v v * R_{i} v u \rightarrow_{\star} R_{i} v u, R_{i} \\
& \left.v u * R_{i} u v \rightarrow_{\star} R_{i} v v, R_{i} v u * R_{i} u u \rightarrow_{\star} R_{i} v u\right\} .
\end{aligned}
$$

For instance, if we take the minimum t-norm, we obtain:

$$
\mathrm{R}_{1} \mathrm{vv} * \mathrm{R}_{1} \mathrm{vu} \rightarrow_{\star} \mathrm{R}_{1} \mathrm{vu}=0.7 * 0.5 \rightarrow_{\star} 0.5=\min \{0.7,0.5\} \rightarrow_{\star} 0.5=1 .
$$

By proceeding similarly with all the terms we obtain:

$$
\begin{aligned}
& \left\|\operatorname{Trans}\left(\mathrm{R}_{1}\right)\right\|=\inf \{1,1,1,1,1,1,1,1\}=1, \\
& \left\|\operatorname{Trans}\left(\mathrm{R}_{2}\right)\right\|=\inf \{1,1,0.7,1,1,1,0.2,1\}=0.2, \\
& \left\|\operatorname{Trans}\left(\mathrm{R}_{3}\right)\right\|=\inf \{1,1,1,1,1,1,1,1\}=1 .
\end{aligned}
$$

If we take the t-norm of $\mathrm{Lukasiewicz}$, the transitivity degrees corresponding to $\operatorname{Trans}\left(\mathrm{R}_{\mathbf{i}}\right)$ are the following: $\left\|\operatorname{Trans}\left(\mathrm{R}_{1}\right)\right\|=1$, $\left\|\operatorname{Trans}\left(\mathrm{R}_{2}\right)\right\|=0.2$, and $\left\|\operatorname{Trans}\left(\mathrm{R}_{3}\right)\right\|=1$.

In FCT there are two notions of similarity, the strong one defined using the strong conjunction $\&$, and the weak one define using the weak conjunction $\wedge$. They are defined as sentences in the following way:

Definition 2 (Cf. [Běhounek et al., 2008]) Let R be a binary predicate symbol,

Strong similarity: $\operatorname{Sim}(\mathrm{R}) \equiv_{\mathrm{df}} \operatorname{Refl}(\mathrm{R}) \& \operatorname{Sym}(\mathrm{R}) \& \operatorname{Trans}(\mathrm{R})$

Weak similarity: $\quad w \operatorname{Sim}(\mathrm{R}) \equiv_{\mathrm{df}} \operatorname{Refl}(\mathrm{R}) \wedge \operatorname{Sym}(\mathrm{R}) \wedge \operatorname{Trans}(\mathrm{R})$ 
Following the Example 1 above, taking the Łukasiewicz t-norm, the degree of weak similarity for each $R_{i}$ is the following:

$\left\|\mathrm{w} \operatorname{Sim}\left(\mathrm{R}_{1}\right)\right\|=\min \left\{\left\|\operatorname{Refl}\left(\mathrm{R}_{1}\right)\right\|,\left\|\operatorname{Sym}\left(\mathrm{R}_{1}\right)\right\|,\left\|\operatorname{Trans}\left(\mathrm{R}_{1}\right)\right\|\right\}=\min \{0.7,0.2,1\}=0.2$,

$\left\|\mathrm{w} \operatorname{Sim}\left(\mathrm{R}_{2}\right)\right\|=\min \left\{\left\|\operatorname{Refl}\left(\mathrm{R}_{2}\right)\right\|,\left\|\operatorname{Sym}\left(\mathrm{R}_{2}\right)\right\|,\left\|\operatorname{Trans}\left(\mathrm{R}_{2}\right)\right\|\right\}=\min \{0.2,1,0.2\}=0.2$,

$\left\|\mathrm{w} \operatorname{Sim}\left(\mathrm{R}_{3}\right)\right\|=\min \left\{\left\|\operatorname{Refl}\left(\mathrm{R}_{3}\right)\right\|,\left\|\operatorname{Sym}\left(\mathrm{R}_{3}\right)\right\|,\left\|\operatorname{Trans}\left(\mathrm{R}_{3}\right)\right\|\right\}=\min \{1,0.6,1\}=0.6$,

and the degree of strong similarity for each $R_{i}$ is:

$$
\begin{aligned}
\left\|\operatorname{Sim}\left(\mathrm{R}_{1}\right)\right\| & =\max \left\{0,\left\|\operatorname{Refl}\left(\mathrm{R}_{1}\right)\right\|+\left\|\operatorname{Sym}\left(\mathrm{R}_{1}\right)\right\|+\left\|\operatorname{Trans}\left(\mathrm{R}_{1}\right)\right\|-2\right\}= \\
& =\max \{0,0.7+0.5+1-2\}=0.2, \\
\left\|\operatorname{Sim}\left(\mathrm{R}_{2}\right)\right\| & =\max \left\{0,\left\|\operatorname{Refl}\left(\mathrm{R}_{2}\right)\right\|+\left\|\operatorname{Sym}\left(\mathrm{R}_{2}\right)\right\|+\left\|\operatorname{Trans}\left(\mathrm{R}_{2}\right)\right\|-2\right\}= \\
& =\max \{0,0.2+1+0.2-2\}=0, \\
\left\|\operatorname{Sim}\left(\mathrm{R}_{3}\right)\right\| & =\max \left\{0,\left\|\operatorname{Refl}\left(\mathrm{R}_{3}\right)\right\|+\left\|\operatorname{Sym}\left(\mathrm{R}_{3}\right)\right\|+\left\|\operatorname{Trans}\left(\mathrm{R}_{3}\right)\right\|-2\right\}= \\
& =\max \{0,1+0.6+1-2\}=0.6 .
\end{aligned}
$$

Notice that in general, when we take the minimum t-norm both similarities coincide. In this paper we will focus mainly on the strong similarity and the analysis of the weak similarity remains as future work.

\section{Local and Global Similarities in Fuzzy Class Theory: Main Results}

Now we will proceed to prove the logical main results of this paper concerning the relationship between local and global similarities. We show that basic properties of local similarities are preserved when we define a global similarity between objects, using these local similarities.

Let $U$ be a set of objects represented by attribute-value pairs. Let $A_{1}, \ldots, A_{k}$ be the attributes used to describe the objects in $U$. Suppose that every attribute $A_{i}$ takes values in a set $\mathrm{V}_{\mathrm{i}}$. For every $\mathrm{i}, 1 \leq \mathrm{i} \leq \mathrm{k}$, let $\mathrm{S}_{\mathrm{i}}$ be a binary fuzzy relation defined on $V_{i}$. Each relation $S_{i}$ induces a relation $R_{i}$ on $U$ as follows. For every $u, v \in U$, $\mathrm{u}=\mathrm{hu}_{1}, \ldots, \mathrm{u}_{\mathrm{k}} \mathbf{i}$ and $\mathrm{v}=\mathrm{h}_{\mathrm{v}}, \ldots, \mathrm{v}_{\mathrm{k}} \mathbf{i}$, we define:

$$
\mathrm{R}_{\mathrm{i}} u v \equiv_{\mathrm{df}} \mathrm{S}_{\mathrm{i}} \mathrm{u}_{\mathrm{i}} \mathrm{v}_{\mathrm{i}}
$$

We call each $\mathrm{R}_{\mathrm{i}}$ a local relation. From these local relations, and using a t-norm *, we define a new relation $\mathrm{R}$ as follows:

$$
\operatorname{Ruv} \equiv_{\mathrm{df}} \mathrm{R}_{1} \mathrm{uv} * \cdots * \mathrm{R}_{\mathrm{k}} \mathrm{uv} \text {. }
$$

We say that $\mathrm{R}$ is a global relation.

Example 2 Table 3 shows the description of three persons according the degree they like three hobbies: trekking, reading, and cinema. In order to compare them we have to define a measure of how similar are two of these values. Let us suppose that we use the following formula to establish the similarity between two values:

$$
\mathrm{R}_{\mathrm{i}} \mathrm{uv}=1-\left|\mathrm{u}_{\mathrm{i}}-\mathrm{v}_{\mathrm{i}}\right| .
$$

Now we use this expression to calculate the similarity between all the hobbies. For instance, concerning trekking John, Mary and Peter have the following degrees of similarity: 
Table 3: Descriptions of three persons using the attributes trekking, reading, and cinema that describe the degree in which a person likes the hobby.

\begin{tabular}{|c|c|c|c|}
\hline Name & trekking & reading & cinema \\
\hline John & 0.5 & 0.3 & 0.9 \\
Mary & 0.6 & 0.8 & 0.7 \\
Peter & 0.9 & 0.5 & 0.4 \\
\hline
\end{tabular}

- $\mathrm{R}_{\mathrm{t}}(\mathrm{John}$, Mary $)=1-|0.5-0.6|=0.9$

- $\mathrm{R}_{\mathrm{r}}(\mathrm{John}$, Peter $)=1-|0.5-0.9|=0.6$

- $\mathrm{R}_{\mathrm{c}}($ Mary, Peter $)=1-|0.6-0.9|=0.7$

Expressed as matrices the relations trekking $\left(\mathrm{R}_{\mathrm{t}}\right)$, reading $\left(\mathrm{R}_{\mathrm{r}}\right)$, and cinema $\left(\mathrm{R}_{\mathrm{c}}\right)$ are the following:

$$
\mathrm{R}_{\mathbf{t}}=\begin{array}{llll}
1 & 0.9 & 0.6 \\
0.9 & 1 & 0.7 \\
0.6 & 0.7 & 1
\end{array} \quad \mathrm{R}_{\mathrm{r}}=\begin{array}{ccc}
1 & 0.5 & 0.8 \\
0.5 & 1 & 0.7 \\
0.8 & 0.7 & 1
\end{array} \quad \mathrm{R}_{\mathrm{c}}=\begin{array}{ccc}
1 & 0.8 & 0.5 \\
0.8 & 1 & 0.7 \\
0.5 & 0.7 & 1
\end{array}
$$

The global relation is Ruv $\equiv_{d f} R_{t} u v * R_{1} u v * R_{c} u v$. and its matrix is computed in the following way:

$$
\mathrm{R}_{*}=\begin{array}{lll}
\mathrm{a}_{11}^{\mathrm{t}} * \mathrm{a}_{11}^{\mathrm{r}} * \mathrm{a}_{11}^{\mathrm{c}} & \mathrm{a}_{12}^{\mathrm{t}} * \mathrm{a}_{12}^{\mathrm{r}} * \mathrm{a}_{12}^{\mathrm{c}} & \mathrm{a}_{13}^{\mathrm{t}} * \mathrm{a}_{13}^{\mathrm{r}} * \mathrm{a}_{13}^{\mathrm{c}} \\
\mathrm{a}_{21}^{\mathrm{t}} * \mathrm{a}_{21}^{\mathrm{r}} * \mathrm{a}_{21}^{\mathrm{c}} & \mathrm{a}_{22}^{\mathrm{t}} * \mathrm{a}_{22}^{\mathrm{r}} * \mathrm{a}_{22}^{\mathrm{c}} & \mathrm{a}_{23}^{\mathrm{t}} * \mathrm{a}_{23}^{\mathrm{r}} * \mathrm{a}_{23}^{\mathrm{c}} \\
\mathrm{a}_{31}^{\mathrm{t}} * \mathrm{a}_{31}^{\mathrm{r}} * \mathrm{a}_{31}^{\mathrm{c}} & \mathrm{a}_{32}^{\mathrm{t}} * \mathrm{a}_{32}^{\mathrm{r}} * \mathrm{a}_{32}^{\mathrm{c}} & \mathrm{a}_{33}^{\mathrm{t}} * \mathrm{a}_{33}^{\mathrm{r}} * \mathrm{a}_{33}^{\mathrm{c}}
\end{array}
$$

where $a_{i j}^{t}, a_{i j}^{r}$ and $a_{i j}^{c}$ stand for the element $(i, j)$ of the matrices $R_{t}, R_{r}$ and $R_{c}$ respectively. If we consider that $*$ is the minimum $t$-norm we have

$$
\mathrm{R}_{\min }=\begin{array}{ccc}
1 & 0.5 & 0.5 \\
0.5 & 1 & 0.7 \\
0.5 & 0.7 & 1
\end{array}
$$

and, considering that $*$ is the Lukasiewicz $\mathbf{t}$-norm we have

$$
\mathrm{R}_{\mathrm{L}}=\begin{array}{ccc}
1 & 0.2 & 0 \\
0.2 & 1 & 0.1 \\
0 & 0.1 & 1
\end{array}
$$

Intuitively, the following proposition shows that the properties of reflexivity, symmetry and transitivity of fuzzy binary relations at the global level inherit the properties of the fuzzy binary relations at the local level when we fusion them.

Proposition 1 Fixed a natural number $\mathrm{k} \geq 1$, let $\mathrm{R}_{1}, \ldots, \mathrm{R}_{\mathrm{k}}$ be binary predicate symbols from the language of FCT, $R_{1} x y, \ldots, R_{k} x y$ atomic formulas, and Rxy $=$ $\mathrm{R}_{1} \mathrm{xy} \& \cdots \& \mathrm{R}_{\mathrm{k}} \mathrm{xy}$. Then, the following theorems are provable in FCT:

$(\mathrm{TS} 1) \quad \operatorname{Refl}\left(\mathrm{R}_{1}\right) \& \cdots \& \operatorname{Refl}\left(\mathrm{R}_{\mathrm{k}}\right) \rightarrow \operatorname{Refl}(\mathrm{R})$

$(\mathrm{TS} 2) \quad \operatorname{Sym}\left(\mathrm{R}_{1}\right) \& \cdots \& \operatorname{Sym}\left(\mathrm{R}_{\mathrm{k}} \rightarrow \operatorname{Sym}(\mathrm{R})\right.$

$(\mathrm{TS} 3) \quad \operatorname{Trans}\left(\mathrm{R}_{1}\right) \& \cdots \& \operatorname{Trans}\left(\mathrm{R}_{\mathrm{k}}\right) \rightarrow \operatorname{Trans}(\mathrm{R})$ 
Proof: Along the proof of this Proposition, we apply repeatedly the following theorem of FCT (see for instance [Běhounek et al., 2008, Lemma B.8 (L15)]):

$$
{ }_{\mathrm{FCT}}(\forall \mathrm{x}) \phi_{1} \& \cdots \&(\forall \mathrm{x}) \phi_{\mathrm{k}} \rightarrow(\forall \mathrm{x})\left(\phi_{1} \& \cdots \& \phi_{\mathrm{k}}\right)
$$

and we also apply the following theorem of FCT (see for instance [Běhounek and Cintula, 2006, Lemma 3.2.2(3)]):

$$
{ }_{\mathrm{FCT}}\left(\phi_{1} \rightarrow \psi_{1}\right) \& \cdots \&\left(\phi_{\mathrm{k}} \rightarrow \psi_{\mathrm{k}}\right) \rightarrow\left(\phi_{1} \& \cdots \& \phi_{\mathrm{k}} \rightarrow \psi_{1} \& \cdots \& \psi_{\mathrm{k}}\right) .
$$

(TS1): By Definition $1, \operatorname{Refl}\left(\mathrm{R}_{1}\right) \& \cdots \& \operatorname{Refl}\left(\mathrm{R}_{\mathrm{k}}\right)=(\forall \mathrm{x}) \mathrm{R}_{1} \mathrm{xx} \& \cdots \&(\forall \mathrm{x}) \mathrm{R}_{\mathrm{k}} \mathrm{xx}$. By applying (1), we have:

$$
{ }_{\mathrm{FCT}}(\forall \mathrm{x}) \mathrm{R}_{1} \mathrm{xx} \& \cdots \&(\forall \mathrm{x}) \mathrm{R}_{\mathrm{k}} \mathrm{xx} \rightarrow(\forall \mathrm{x})\left(\mathrm{R}_{1} \mathrm{xx} \& \cdots \& \mathrm{R}_{\mathrm{k}} \mathrm{xx}\right)
$$

and since $(\forall x)\left(R_{1} x x \& \cdots \& R_{k} x x\right)=\operatorname{Refl}(R)$, we have

$$
\operatorname{Refl}\left(\mathrm{R}_{1}\right) \& \cdots \& \operatorname{Refl}\left(\mathrm{R}_{\mathrm{k}}\right) \rightarrow \operatorname{Refl}(\mathrm{R}) .
$$

(TS2): By Definition $1, \operatorname{Sym}\left(\mathrm{R}_{1}\right) \& \cdots \& \operatorname{Sym}\left(\mathrm{R}_{\mathrm{k}}\right)=$

$$
=(\forall x, y)\left(R_{1} x y \rightarrow R_{1} y x\right) \& \cdots \&(\forall x, y)\left(R_{k} x y \rightarrow R_{k} y x\right) .
$$

Now, by applying two times (1), we obtain:

${ }_{\text {FCT }}(\forall x, y)\left(R_{1} x y \rightarrow R_{1} y x\right) \& \cdots \&(\forall x, y)\left(R_{k} x y \rightarrow R_{k} y x\right) \rightarrow$

By applying (2) we obtain:

$$
\rightarrow(\forall x, y)\left(\left(R_{1} x y \rightarrow R_{1} y x\right) \& \cdots \&\left(R_{k} x y \rightarrow R_{k} y x\right)\right) .
$$

$$
\text { FCT }(\forall x, y)\left(\left(R_{1} x y \rightarrow R_{1} y x\right) \& \cdots \&\left(R_{k} x y \rightarrow R_{k} y x\right)\right) \rightarrow
$$

Finally, by transitivity, we obtain:

$$
\rightarrow(\forall x, y)\left(R_{1} x y \& \cdots \& R_{k} x y \rightarrow R_{1} y x \& \cdots \& R_{k} y x\right) .
$$

$$
\begin{aligned}
& { }_{\text {FCT }}(\forall x, y)\left(R_{1} x y \rightarrow R_{1} y x\right) \& \cdots \&(\forall x, y)\left(R_{k} x y \rightarrow R_{k} y x\right) \rightarrow \\
& (\forall x, y)\left(R_{1} x y \& \cdots \& R_{k} x y \rightarrow R_{1} y x \& \cdots \& R_{k} y x\right) \text {. }
\end{aligned}
$$

Consequently, $\operatorname{Sym}\left(\mathrm{R}_{1}\right) \& \cdots \& \operatorname{Sym}\left(\mathrm{R}_{\mathrm{k}}\right) \rightarrow \operatorname{Sym}(\mathrm{R})$.

(TS3): By Definition 1, $\operatorname{Trans}\left(\mathrm{R}_{1}\right) \& \ldots \& \operatorname{Trans}\left(\mathrm{R}_{1}\right)=$

$$
=(\forall x, y, z)\left(R_{1} x y \& R_{1} y z \rightarrow R_{1} x z\right) \& \cdots \&(\forall x, y, z)\left(R_{k} x y \& R_{k} y z \rightarrow R_{k} x z\right) .
$$

Now, by applying three times (1), we obtain:

${ }_{\text {FCT }}(\forall x, y, z)\left(R_{1} x y \& R_{1} y z \rightarrow R_{1} x z\right) \& \cdots \&(\forall x, y, z)\left(R_{k} x y \& R_{k} y z \rightarrow R_{k} x z\right) \rightarrow$

$$
\rightarrow(\forall x, y, z)\left(\left(R_{1} x y \& R_{1} y z \rightarrow R_{1} x z\right) \& \cdots \&\left(R_{k} x y \& R_{k} y z \rightarrow R_{k} x z\right)\right) .
$$

By applying (2) we obtain:

$$
\text { FCT }(\forall x, y, z)\left(\left(R_{1} x y \& R_{1} y z \rightarrow R_{1} x z\right) \& \cdots \&\left(R_{k} x y \& R_{k} y z \rightarrow R_{k} x z\right)\right) \rightarrow
$$

$\rightarrow(\forall x, y, z)\left(\left(R_{1} x y \& R_{1} y z\right) \& \cdots \&\left(R_{k} x y \& R_{k} y z\right) \rightarrow\left(R_{1} x z \& \cdots \& R_{k} x z\right)\right)$.

By repeatedly applying the commutativity and associativity axioms for \& we obtain: FCT $(\forall x, y, z)\left(\left(R_{1} x y \& R_{1} y z\right) \& \cdots \&\left(R_{k} x y \& R_{k} y z\right) \rightarrow\left(R_{1} x z \& \cdots \& R_{k} x z\right)\right) \rightarrow$

$\rightarrow(\forall x, y, z)\left(\left(R_{1} x y \& \cdots \& R_{k} x y\right) \&\left(R_{1} y z \& \cdots \& R_{k} y z\right) \rightarrow\left(R_{1} x z \& \cdots \& R_{k} x z\right)\right)$.

That is, by definition of the atomic formula $\mathrm{Rxy}$,

FCT $(\forall x, y, z)\left(\left(R_{1} x y \& R_{1} y z\right) \& \cdots \&\left(R_{k} x y \& R_{k} y z\right) \rightarrow\left(R_{1} x z \& \cdots \& R_{k} x z\right)\right) \rightarrow$

$\rightarrow(\forall x, y, z)(R x y \& R y z \rightarrow R x z)$.

The consequent formula of the previous sentence is precisely $\operatorname{Trans}(\mathrm{R})$. Thus, by transitivity, we obtain ' ${ }_{F C T} \operatorname{Trans}\left(\mathrm{R}_{1}\right) \& \cdots \& \operatorname{Trans}\left(\mathrm{R}_{\mathrm{k}}\right) \rightarrow \operatorname{Trans}(\mathrm{R})$. 
Following with Example 2, we see that the relations $R_{t}, R_{r}$ and $R_{c}$ are reflexive and symmetric to a degree 1 since all the elements in the diagonal of the matrices are 1 and the matrices are all symmetric. Also, the matrices representing the global similarity taking both the minimum $t$-norm $\left(R_{\min }\right)$ and the Lukasiewicz $t$-norm $\left(R_{L}\right)$ have 1 in the diagonal and are symmetric. The relations $R_{t}, R_{r}$ and $R_{c}$ are not transitive if we take the minimum t-norm. To see this, we must see that there are some elements $\mathrm{x}, \mathrm{y}, \mathrm{z}$ such that for $\mathrm{R} \in\left\{\mathrm{R}_{\mathrm{t}}, \mathrm{R}_{\mathrm{r}}, \mathrm{R}_{\mathrm{c}}\right\}$, the inequalities $\mathrm{R}(\mathrm{x}, \mathrm{y}) * \mathrm{R}(\mathrm{y}, \mathrm{z}) \leq \mathrm{R}(\mathrm{x}, \mathrm{z})$ are not satisfied. Indeed,

- $\mathrm{R}_{\mathrm{t}}($ John, Mary $) * \mathrm{R}_{\mathrm{t}}($ Mary, Peter $) \quad \mathrm{R}_{\mathrm{t}}($ John, Peter $)$, since $\min \{0.9,0.7\}=$ 0.7 and $R_{t}($ John, Peter $)=0.6$

- $\mathrm{R}_{\mathrm{r}}($ John, Peter $) \star \mathrm{R}_{\mathrm{r}}$ (Peter, Mary) $\quad \mathrm{R}_{\mathrm{r}}($ John, Mary), since $\min \{0.8,0.7\}=$ 0.7 and $\mathrm{R}_{\mathrm{r}}$ (John, Mary) $=0.5$

- $\mathrm{R}_{\mathrm{c}}$ (John, Mary) $* \mathrm{R}_{\mathrm{c}}$ (Mary, Peter $) \quad \mathrm{R}_{\mathrm{c}}$ (John, Peter $)$, since $\min \{0.8,0.7\}=$ 0.7 but $\mathrm{R}_{\mathrm{c}}(\mathrm{John}$, Peter $)=0.5$

Therefore, the local relations have a degree of transitivity strictly lower than 1 taking the minimum $\mathrm{t}$-norm. An easy computation shows that in this case the transitivity degree of each one of the local relations is the following: $\left\|\operatorname{Trans}\left(\mathrm{R}_{t}\right)\right\|=0.6$, $\left\|\operatorname{Trans}\left(\mathrm{R}_{\mathrm{r}}\right)\right\|=0.5$, and $\left\|\operatorname{Trans}\left(\mathrm{R}_{\mathrm{c}}\right)\right\|=0.5$. According to Proposition 1 , the degree of transitivity of the global relation has to be greater or equal than 0.5 which is the minimum of the values of local transitivities. Indeed, by computing directly from the global matrix $R_{\min }$ we see that $\left\|\operatorname{Trans}\left(\mathrm{R}_{\min }\right)\right\|=0.5$. Therefore, as it was expected,

$$
\left\|\operatorname{Trans}\left(\mathrm{R}_{\mathrm{t}}\right) \& \operatorname{Trans}\left(\mathrm{R}_{\mathrm{t}}\right) \& \operatorname{Trans}\left(\mathrm{R}_{\mathrm{t}}\right)\right\|=0.5 \leq 0.5=\left\|\operatorname{Trans}\left(\mathrm{R}_{\min }\right)\right\| .
$$

Taking the Łukasiewicz t-norm, it is not difficult to see that all of them $R_{t}, R_{r}$ and $\mathrm{R}_{\mathrm{c}}$ are transitive. According to Proposition 1, the global relation has also transitivity degree 1 .

Now, as it is proved in the following corollary of the previous proposition, a lower bound of the degree of similarity of a global relation can be calculated by using the degrees of similarity of the local relations.

Corollary 1 Fixed a natural number $\mathrm{k} \geq 1$, let $\mathrm{R}_{1}, \ldots, \mathrm{R}_{\mathrm{k}}$ be binary predicate symbols from the language of FCT, $\mathrm{R}_{1} \mathrm{xy}, \ldots, \mathrm{R}_{\mathrm{k}} \mathrm{xy}$ atomic formulas, and $\mathrm{Rxy}=\mathrm{R}_{1} \mathrm{xy} \&$ $\cdots \& \mathrm{R}_{\mathrm{k}} \mathrm{xy}$. Then, the following theorems are provable in FCT:

(TS4) $\operatorname{Sim}\left(\mathrm{R}_{1}\right) \& \cdots \& \operatorname{Sim}\left(\mathrm{R}_{\mathrm{k}}\right) \rightarrow \operatorname{Sim}(\mathrm{R})$,

(TS5) $\quad \mathrm{wSim}\left(\mathrm{R}_{1}\right) \wedge \cdots \wedge \mathrm{wSim}\left(\mathrm{R}_{\mathrm{k}}\right) \rightarrow \mathrm{wSim}(\mathrm{R})$.

Proof: (TS4): By Definition 2, we have $\operatorname{Sim}\left(\mathrm{R}_{1}\right) \& \cdots \& \operatorname{Sim}\left(\mathrm{R}_{\mathrm{k}}\right)=$ $=\operatorname{Refl}\left(\mathrm{R}_{1}\right) \& \operatorname{Sym}\left(\mathrm{R}_{1}\right) \& \operatorname{Trans}\left(\mathrm{R}_{1}\right) \& \cdots \& \operatorname{Refl}\left(\mathrm{R}_{\mathrm{k}}\right) \& \operatorname{Sym}\left(\mathrm{R}_{\mathrm{k}}\right) \& \operatorname{Trans}\left(\mathrm{R}_{\mathrm{k}}\right)$. Observe that, using the axioms of commutativity and associativity for $\&$, we get:

${ }_{\text {FCT }} \operatorname{Sim}\left(\mathrm{R}_{1}\right) \& \cdots \& \operatorname{Sim}\left(\mathrm{R}_{\mathrm{k}}\right) \rightarrow$

$\rightarrow \operatorname{Refl}\left(\mathrm{R}_{1}\right) \& \cdots \& \operatorname{Refl}\left(\mathrm{R}_{\mathrm{k}}\right) \& \operatorname{Sym}\left(\mathrm{R}_{1}\right) \& \cdots \& \operatorname{Sym}\left(\mathrm{R}_{\mathrm{k}}\right) \& \operatorname{Trans}\left(\mathrm{R}_{1}\right) \& \cdots \& \operatorname{Trans}\left(\mathrm{R}_{\mathrm{k}}\right)$.

Now we use the fact that if $\alpha_{1}, \ldots \alpha_{k}$ are theorems of FCT, then $\alpha_{1} \& \cdots \& \alpha_{k}$ is also a theorem of FCT. From (TS1), (TS2) and (TS3) of Proposition 1, using (2), we obtain that the following formula is a theorem of FCT:

$\operatorname{Refl}\left(\mathrm{R}_{1}\right) \& \cdots \& \operatorname{Refl}\left(\mathrm{R}_{\mathrm{k}}\right) \& \operatorname{Sym}\left(\mathrm{R}_{1}\right) \& \cdots \& \operatorname{Sym}\left(\mathrm{R}_{\mathrm{k}}\right) \& \operatorname{Trans}\left(\mathrm{R}_{1}\right) \& \cdots \& \operatorname{Trans}\left(\mathrm{R}_{\mathrm{k}}\right) \rightarrow$ $\rightarrow \operatorname{Refl}(\mathrm{R}) \& \operatorname{Sym}(\mathrm{R}) \& \operatorname{Trans}(\mathrm{R})$ 
The consequent formula of the previous sentence is precisely $\operatorname{Sim}(\mathrm{R})$. Finally, by transitivity we get ' ${ }_{\mathrm{FCT}} \operatorname{Sim}\left(\mathrm{R}_{1}\right) \& \cdots \& \operatorname{Sim}\left(\mathrm{R}_{\mathrm{k}}\right) \rightarrow \operatorname{Sim}(\mathrm{R})$.

(TS5): It is analogously proved by using the following theorem (3) (see for instance [Běhounek and Cintula, 2006, Lemma 3.2.2(4)]) instead of (2):

$$
{ }_{\mathrm{FCT}}\left(\phi_{1} \rightarrow \psi_{1}\right) \wedge \cdots \wedge\left(\phi_{\mathrm{k}} \rightarrow \psi_{\mathrm{k}}\right) \rightarrow\left(\phi_{1} \wedge \cdots \wedge \phi_{\mathrm{k}} \rightarrow \psi_{1} \wedge \cdots \wedge \psi_{\mathrm{k}}\right) .
$$

To illustrate the consequences of the previous corollary, we use again Example 2. We calculate here the degree of similarity of the global relation from the degree of similarity of each one of the local similarities. First let us focus on $\mathrm{R}_{\mathbf{t}}$. According to Definition 2, its degree of strong similarity is computed as the truth value of the sentence $\operatorname{Sim}\left(\mathrm{R}_{\mathrm{t}}\right)=\operatorname{Refl}\left(\mathrm{R}_{\mathrm{t}}\right) \& \operatorname{Sym}\left(\mathrm{R}_{\mathrm{t}}\right) \& \operatorname{Trans}\left(\mathrm{R}_{\mathrm{t}}\right)$. We know that using the minimum t-norm, $\left\|\operatorname{Refl}\left(\mathrm{R}_{\mathrm{t}}\right)\right\|=\left\|\operatorname{Sym}\left(\mathrm{R}_{\mathrm{t}}\right)\right\|=1$ and $\left\|\operatorname{Trans}\left(\mathrm{R}_{\mathrm{t}}\right)\right\|=0.6$. Therefore, we have $\left\|\operatorname{Sim}\left(R_{t}\right)\right\|=0.6$. Proceeding analogously with $R_{r}$ and $R_{c}$ using the minimum t-norm, we have the following values: $\left\|\operatorname{Sim}\left(R_{r}\right)\right\|=1$ and $\left\|\operatorname{Sim}\left(R_{c}\right)\right\|=1$.

According to Corollary 1 , the degree of similarity of the global relation has to be greater or equal than 0.5 which is the minimum of the degrees of local similarities. If we compute $\left\|\operatorname{Sim}\left(\mathrm{R}_{\min }\right)\right\|$ directly, using the minimum t-norm we have that $\left\|\operatorname{Refl}\left(\mathrm{R}_{\min }\right)\right\|=\left\|\operatorname{Sym}\left(\mathrm{R}_{\min }\right)\right\|=1$ and $\left\|\operatorname{Trans}\left(\mathrm{R}_{\min }\right)\right\|=0.5$. Therefore, as it is expected,

$$
\left\|\operatorname{Sim}\left(R_{t}\right) \& \operatorname{Sim}\left(R_{r}\right) \& \operatorname{Sim}\left(R_{c}\right)\right\|=0.5 \leq 0.5=\left\|\operatorname{Sim}\left(R_{\min }\right)\right\| .
$$

Because the definition of weak similarity, namely wSim, interprets the conjunction $\wedge$ as the minimum, the values for $\operatorname{Refl}\left(R_{t}\right), \operatorname{Sym}\left(R_{t}\right)$ and $\operatorname{Trans}\left(R_{t}\right)$ are the same than the strong similarity.

The following proposition shows that the global similarity is a congruence if some of the local similarities are also congruences.

Proposition 2 Fixed a natural number $\mathrm{k} \geq 1$, let $\mathrm{R}_{1}, \ldots, \mathrm{R}_{\mathrm{k}}$ be binary predicate symbols from the language of FCT, $\mathrm{R}_{1} \mathrm{xy}, \ldots, \mathrm{R}_{\mathrm{k}} \mathrm{xy}$ atomic formulas and $\mathrm{Rxy}=$ $\mathrm{R}_{1} \mathrm{xy} \& \cdots \& \mathrm{R}_{\mathrm{k}} \mathrm{xy}$. Assume that $\mathrm{T}$ is a theory such that, for some $\mathrm{i}(1 \leq \mathrm{i} \leq \mathrm{k})$, and for each n-ary predicate $P$,

$\mathrm{T}_{\text {FCT }}\left(\forall \mathrm{x}_{1}, \ldots, \mathrm{x}_{\mathrm{n}}, \mathrm{y}_{1}, \ldots, \mathrm{y}_{\mathrm{n}}\right)\left(\mathrm{x}_{1} \mathrm{R}_{\mathrm{i}} \mathrm{y}_{1} \& \cdots \& \mathrm{x}_{\mathrm{n}} \mathrm{R}_{\mathrm{i}} \mathrm{y}_{\mathrm{n}} \rightarrow\left(\mathrm{P} \mathrm{x}_{1} \ldots \mathrm{x}_{\mathrm{n}} \leftrightarrow \mathrm{P} \mathrm{y}_{1} \ldots \mathrm{y}_{\mathrm{n}}\right)\right)$.

Then, the following property holds for R: For each n-ary predicate $\mathrm{P}$,

$$
\mathrm{T}{ }_{\mathrm{FCT}}\left(\forall \mathrm{x}_{1}, \ldots, \mathrm{x}_{\mathrm{n}}, \mathrm{y}_{1}, \ldots, \mathrm{y}_{\mathrm{n}}\right)\left(\mathrm{x}_{1} \mathrm{Ry}_{1} \& \cdots \& \mathrm{x}_{\mathrm{n}} \mathrm{Ry_{n }} \rightarrow\left(\mathrm{P}_{1} \ldots \mathrm{x}_{\mathrm{n}} \leftrightarrow \mathrm{P} \mathrm{y}_{1} \ldots \mathrm{y}_{\mathrm{n}}\right)\right) \text {. }
$$

Proof: For the sake of clarity we prove the proposition for every binary predicate P, but the same proof holds for predicates of arbitrary arity. Let $\mathrm{i}, 1 \leq \mathrm{i} \leq \mathrm{k}$, be such that or each n-ary predicate $\mathrm{P}$,

$\mathrm{T}^{-}{ }_{\mathrm{FCT}}\left(\forall \mathrm{x}_{1}, \ldots, \mathrm{x}_{\mathrm{n}}, \mathrm{y}_{1}, \ldots, \mathrm{y}_{\mathrm{n}}\right)\left(\mathrm{x}_{1} \mathrm{R}_{\mathrm{i}} \mathrm{y}_{1} \& \cdots \& \mathrm{x}_{\mathrm{n}} \mathrm{R}_{\mathrm{i}} \mathrm{y}_{\mathrm{n}} \rightarrow\left(\mathrm{P} \mathrm{x}_{1} \ldots \mathrm{x}_{\mathrm{n}} \leftrightarrow \mathrm{P} \mathrm{y}_{1} \ldots \mathrm{y}_{\mathrm{n}}\right)\right)$.

Let us consider the following instance of the axiom (MTL1):

(?) $\quad\left(\mathrm{Rx}_{1} \mathrm{y}_{1} \& \mathrm{Rx}_{2} \mathrm{y}_{2} \rightarrow \mathrm{R}_{\mathrm{i}} \mathrm{x}_{1} \mathrm{y}_{1} \& \mathrm{R}_{\mathrm{i}} \mathrm{x}_{2} \mathrm{y}_{2}\right) \rightarrow$

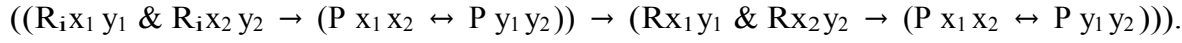

On the one hand, since $\mathrm{Rxy}=\mathrm{R}_{1} \mathrm{xy} \& \cdots \& \mathrm{R}_{\mathrm{k}} \mathrm{xy}$, using the theorem

$$
{ }_{\mathrm{FCT}} \phi_{1} \& \cdots \& \phi_{\mathrm{i}} \& \cdots \& \phi_{\mathrm{k}} \rightarrow \phi_{\mathrm{i}}
$$


we obtain that $\mathrm{Rx}_{1} \mathrm{y}_{1} \rightarrow \mathrm{R}_{\mathrm{i}} \mathrm{x}_{1} \mathrm{y}_{1}$ and $\mathrm{Rx}_{2} \mathrm{y}_{2} \rightarrow \mathrm{R}_{\mathrm{i}} \mathrm{x}_{2} \mathrm{y}_{2}$ are theorems of FCT. Therefore, by applying (1), we have:

$$
{ }_{F C T} R_{1} y_{1} \& R_{2} y_{2} \rightarrow R_{i} x_{1} y_{1} \& R_{i} x_{2} y_{2} \text {. }
$$

On the other hand, by assumption we have:

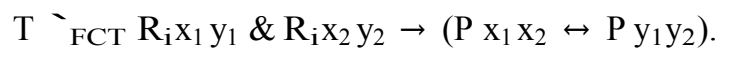

Now, taking as premises (?), (5), and (6), by applying two times Modus Ponens, we obtain:

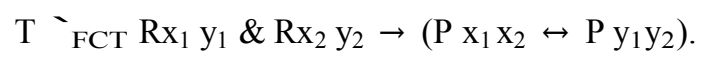

Finally, by applying four times the Generalitation rule to (7), we obtain:

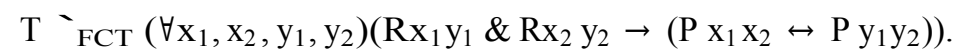

q.e.d.

In [Hájek, 1998, Lemma 5.6.8] it is proved, in the context of the logic BL $\forall$, that similar objects have similar properties, being these properties expressed by first-order formulas evaluated in these objects. In the forthcoming paper [Armengol et al., in press, Theorem 1] we generalized this result to the logic MTL $\forall$. To present here this result, we extend the notion of syntactic degree of a formula in [Hájek, 1998, Definition 5.6.7] to the language of $\mathrm{MTL}_{\Delta} \forall$ in the following way:

1. $\operatorname{dg}(\varphi)=1$, if $\varphi$ is atomic,

2. $\operatorname{dg}(\varphi)=0$, if $\varphi$ is a truth constant,

3. $\operatorname{dg}(\forall x \varphi)=\operatorname{dg}(\exists x \varphi)=\operatorname{dg}(\neg \varphi)=\operatorname{dg}(\Delta \varphi)=\operatorname{dg}(\varphi)$,

4. $\operatorname{dg}(\varphi \rightarrow \psi)=\operatorname{dg}(\varphi * \psi)=\operatorname{dg}(\varphi)+\operatorname{dg}(\psi)$,

5. $\operatorname{dg}(\varphi \wedge \psi)=\operatorname{dg}(\varphi \vee \psi)=\max \{\operatorname{dg}(\varphi), \operatorname{dg}(\psi)\}$.

Notation: Let $\mathrm{x} \approx \approx^{\mathrm{k}} \mathrm{y}$ abbreviate $(\mathrm{x} \approx \mathrm{y}) \& \cdots \&(\mathrm{x} \approx \mathrm{y})(\mathrm{k}$ times $)$.

Theorem 2 ([Armengol et al., in press, Theorem 1]) Let $\mathrm{T}$ be a theory in MTL $\forall$ containing the axioms:

(S1) $\quad(\forall \mathrm{x}) \mathrm{x} \approx \mathrm{x}$

(Reflexivity)

(S2) $\quad(\forall \mathrm{x}, \mathrm{y})(\mathrm{x} \approx \mathrm{y} \rightarrow \mathrm{y} \approx \mathrm{x})$

(Symmetry)

(S3) $\quad(\forall \mathrm{x}, \mathrm{y}, \mathrm{z})(\mathrm{x} \approx \mathrm{y} \& \mathrm{y} \approx \mathrm{z} \rightarrow \mathrm{x} \approx \mathrm{z}) \quad$ (Transitivity)

and, for every $\mathrm{n}$-ary predicate $\mathrm{P}$ of the language, the congruence axiom:

$\left(\forall \mathrm{x}_{1}, \ldots, \mathrm{x}_{\mathrm{n}}, \mathrm{y}_{1}, \ldots, \mathrm{y}_{\mathrm{n}}\right)\left(\mathrm{x}_{1} \approx \mathrm{y}_{1} \& \cdots \& \mathrm{x}_{\mathrm{n}} \approx \mathrm{y}_{\mathrm{n}} \rightarrow\left(\mathrm{P} \mathrm{x}_{1}, \ldots, \mathrm{x}_{\mathrm{n}} \leftrightarrow \mathrm{P}_{1}, \ldots \mathrm{y}_{\mathrm{n}}\right)\right)$. Let $\varphi$ be a first-order formula of $\operatorname{MTL} \forall$ with $\operatorname{dg}(\varphi)=\mathrm{k}$, and let $\mathrm{x}_{1} \ldots, \mathrm{x}_{\mathrm{n}}$ be variables including all free variables of $\varphi$ in such a way that, for every $1 \leq \mathrm{i} \leq \mathrm{n}, \mathrm{y}_{\mathrm{i}}$ is substituable for $\mathbf{x}_{\mathrm{i}}$ in $\varphi$. Then,

$$
\mathrm{T}_{\mathrm{FCT}}\left(\mathrm{x}_{1} \approx^{\mathrm{k}} \mathrm{y}_{1}\right) \& \cdots \&\left(\mathrm{x}_{\mathrm{n}} \approx^{\mathrm{k}} \mathrm{y}_{\mathrm{n}}\right) \rightarrow\left(\varphi\left(\mathrm{x}_{1}, \ldots, \mathrm{x}_{\mathrm{n}}\right) \leftrightarrow \varphi\left(\mathrm{y}_{1}, \ldots, \mathrm{y}_{\mathrm{n}}\right)\right) .
$$

In our context we can use the result only for the fragment without $\Delta$ as the following example shows. Suppose that $\mathrm{k}=1$. Let $\mathrm{M}$ be a $\mathrm{T}$-structure for the minimum as defined in Section 2 in a signature with only a monadic predicate symbol $\mathrm{P}$ and a binary relation symbol $\approx$. Assume that this structure is a model of the axioms (S1), 
$(\mathrm{S} 2),(\mathrm{S} 3)$, and of the axiom of congruence for $\approx$ corresponding to $\mathrm{P}$. This structure is not a model of the formula $(\forall \mathrm{x}, \mathrm{y})(\mathrm{x} \approx \mathrm{y} \rightarrow(\Delta(\mathrm{P} \mathrm{x}) \leftrightarrow \Delta(\mathrm{P} y)))$ : Indeed, take $\mathrm{a}, \mathrm{b}$ to be elements of $\mathrm{M}$ such that $\|\mathrm{a} \approx \mathrm{b}\|_{\mathrm{M}}^{*}=0.9, \mathrm{P}^{\mathrm{M}}(\mathrm{a})=0.9$ and $\mathrm{P}^{\mathrm{M}}(\mathrm{b})=1$.

For formulas containing the connective $\Delta$ we have the following result:

Theorem 3 Let $\mathrm{T}$ be a theory in $\mathrm{MTL}_{\Delta}$ containing axioms (S1), (S2), (S3) and the congruence axioms or $\approx$. Let $\varphi$ be a first-order formula of $\operatorname{MTL}_{\Delta}$ with $\operatorname{dg}(\varphi)=\mathrm{k}$, and let $x_{1} \ldots, x_{n}$ be variables including all free variables of $\varphi$ in such a way that, for every $1 \leq \mathrm{i} \leq \mathrm{n}, \mathrm{y}_{\mathrm{i}}$ is substituable for $\mathrm{x}_{\mathrm{i}}$ in $\varphi$. Then,

$$
\mathrm{T}^{-} \Delta\left[\left(\mathrm{x}_{1} \approx^{\mathrm{k}} \mathrm{y}_{1}\right) \& \cdots \&\left(\mathrm{x}_{\mathrm{n}} \approx^{\mathrm{k}} \mathrm{y}_{\mathrm{n}}\right)\right] \rightarrow\left(\varphi\left(\mathrm{x}_{1}, \ldots, \mathrm{x}_{\mathrm{n}}\right) \leftrightarrow \varphi\left(\mathrm{y}_{1}, \ldots, \mathrm{y}_{\mathrm{n}}\right)\right) .
$$

Proof: By induction on the complexity of formulas. By axioms (S1), (S2), (S3) and congruence axioms, the assertion is true for atomic formulas (and is vacuous for truth constants). For the proof of all the inductive steps except for the $\Delta$ step, we refer to the proof of [Armengol et al., in press, Theorem 1]. For the sake of simplicity, we prove the $\Delta$ step only for 2 variables, that is, for $\mathrm{x} \approx^{\mathrm{k}} \mathrm{y}$ instead for $\left(\mathrm{x}_{1} \approx^{\mathrm{k}} \mathrm{y}_{1}\right) \& \cdots \&\left(\mathrm{x}_{\mathrm{n}} \approx^{\mathrm{k}}\right.$ $\left.\mathrm{y}_{\mathrm{n}}\right)$. The generalization to the $\mathrm{n}$ case is trivial.

Inductive step $\Delta \varphi$. By definition of the syntactic degree, $\operatorname{dg}(\Delta \varphi)=\mathrm{k}$. By inductive hypothesis we have $\mathrm{T}^{-} \mathrm{x} \approx^{\mathrm{k}} \mathrm{y} \rightarrow(\varphi(\mathrm{x}) \leftrightarrow \varphi(\mathrm{y}))$. Thus, by the $\Delta$ rule,

$$
\mathrm{T}-\Delta\left[\left(\mathrm{x} \approx^{\mathrm{k}} \mathrm{y}\right) \rightarrow(\varphi(\mathrm{x}) \leftrightarrow \varphi(\mathrm{y}))\right] .
$$

and then, by Axiom $(\Delta 5)$ of $\mathrm{MTL}_{\Delta}, \mathrm{T}^{-} \Delta\left(\mathrm{x} \approx^{\mathrm{k}} \mathrm{y}\right) \rightarrow \Delta(\varphi(\mathrm{x}) \leftrightarrow \varphi(\mathrm{y}))$. Finally, by using the fact that $\Delta(\phi \& \psi) \leftrightarrow(\Delta \phi \& \Delta \psi)$ is a theorem of MTL $\Delta$ (Cf. [Běhounek and Cintula, 2006, Lemma 3.2.1(T $\Delta 3)]$ ), and using again Axiom ( $\Delta 5)$, it is easy to see that

$$
\mathrm{T}^{-} \Delta\left(\mathrm{x} \approx^{\mathrm{k}} \mathrm{y}\right) \rightarrow(\Delta \varphi(\mathrm{x}) \leftrightarrow \Delta \varphi(\mathrm{y}))
$$

\section{Conclusions and Future Work}

In the present paper we study similarities in the framework of Fuzzy Class Theory (FCT) and prove some logical properties. FCT allow us to deal with relations having different degrees of reflexivity, symmetry and transitivity. We obtain some results that adequately interpreted allow us to say that, taking a t-norm as aggregation operator: the properties of reflexivity, symmetry and transitivity of fuzzy binary relations at the global level inherit the properties of the fuzzy binary relations at the local level when we fusion them. Moreover, we have shown that the global similarity is a congruence if some of the local similarities are congruences.

Fuzzy Description Logics (FDLs) are natural extensions of Description Logics [Baader et al., 2003] expressing vague concepts commonly present in real applications (see [Lukasiewicz and Straccia, 2008] for a survey). In [García-Cerdaña et al., 2010] we studied the notion of similarity between objects represented as attribute-value pairs in the context of Fuzzy Description Logic. In such paper we proposed to add a SBox (Similarity Box) to the knowledge bases of an ALC-like fuzzy description language. The SBox allows the expression of properties such as reflexivity, symmetry, transitivity and congruence of a relation. The results presented in Section 3 of the current paper will be used in a forthcoming paper in order to introduce graded axioms for reflexivity, symmetry and transitivity in the SBox of a FDL in a systematic way. 
An aggregation operator has the property of compensation (also known as Pareto property) when the result of the aggregation is lower than the maximum element aggregated and higher than the minimum one (see [Detyniecki, 2001]). Some authors stress that t-norms (and also t-conorms) lack of a compensation behaviour, what is considered crucial in the aggregation process. In practice, when the property of compensation does not hold, this can produce undesirable effects when two object are similar in all the attributes except in one of them. The operators known as uninorms [Fodor et al., 1997] are a generalization of t-norms in which the neutral element of the operation does not coincide with the maximum. This characteristic implies that these kinds of operations admit in general a good compensating behaviour. As future work we plan to study the FCT based in UL, the logic of uninorms [Metcalfe and Montagna, 2007], in order to deal with similarities in this context. We want to explore the plausibility of the results obtained in the present paper in the more general context of uninorms. We also plan to study other aggregation operators from a logical point of view.

Finally, we want to experiment with the approach introduced in this paper on a real domain. In particular, we are interested on assessing the life quality of people with intellectual disabilities. Schalock and Verdugo [2002] proposed a model where the life quality of a person is a relation of eight dimensions. In fact, the relation between these dimension is unknown, i.e., we do not know how low or high values of one dimension affect the values of the others. We think that with our approach we can model both the similarity between two persons and also the relations between the dimensions.

\section{Acknowledgments}

The authors acknowledge support by the Spanish projects EdeTRI (TIN2012-39348C02-01), COGNITIO (TIN2012-38450-C03-03), MILESS (TIN2013-45039-P), and MTM 2011-25747; and the grants 2014SGR-118 and 2014SGR-788 from the Generalitat de Catalunya.

\section{References}

E. Armengol, P. Dellunde, and A. García-Cerdaña. On similarity in Fuzzy Description Logics. Fuzzy Sets and Systems, in press.

F. Baader, D. Calvanese, D. McGuinness, D. Nardi, and P. Patel-Schneider, editors. The Description Logic Handbook: Theory, Implementation, and Applications. Cambridge University Press, New York, NY, USA, 2003.

L. Běhounek and P. Cintula. Fuzzy Class Theory. Fuzzy Sets and Systems, 154(1): 34-55, 2005.

L. Běhounek and P. Cintula. Fuzzy Class Theory: A primer v1.0. Technical Report V-939, Institute of Computer Science, Academy of Sciences of the Czech Republic, Prague, 2006.

L. Běhounek, U. Bodenhofer, and P. Cintula. Relations in Fuzzy Class Theory. Fuzzy Sets and Systems, 159(14):1729-1772, 2008.

L. Běhounek, P. Cintula, and P. Hájek. A Introduction to Mathematical Fuzzy Logic, chapter I of Handbook of Mathematical Fuzzy Logic - volume 1, pages 1-102. Number 37 in Studies in Logic. College Publications, London, 2011. 
M. Detyniecki. Fundamentals on aggregation operators. Technical report, Computer Science Division. Universiyty of California, Berkeley, 2001. URL http://www. cs.berkeley.edu/ $\sim$ marcin/agop.pdf.

D. Dubois and H. Prade. On the use of aggregation operations in information fusion process. Fuzzy Sets and Systems, 142:143-161, 2004.

J. Fodor, R. Yager, and A. Rybalov. Structure of uninorms. International Journal of Uncertainty, Fuzziness and Knowlegge-based Systems, 5:411-427, 1997.

A. García-Cerdaña, E. Armengol, and P. Dellunde. Similarity for Attribute-value Representations in Fuzzy Description Logics. In R. Alquezar, A. Moreno, and J. Aguilar, editors, Artificial Intelligence Research and Developement. Volume 220 of Frontiers in Artificial Intelligence and Applications. Proceedings of CCIA 2010, volume 210, pages 269-278, 2010.

P. Hájek. Metamathematics of Fuzzy Logic, volume 4 of Trends in Logic. Studia Logica Library. Kluwer Academic Publishers, Dordrecht, 1998.

E. Klement, R. Mesiar, and E. Pap. Triangular Norms, volume 8 of Trends in Logic. Studia Logica Library. Kluwer Academic Publishers, Dordrecht, 2000.

C. Ling. Representation of associative functions. Publicationes Mathematicae Debrecen, 12:189-212, 1965.

T. Lukasiewicz and U. Straccia. Managing uncertainty and vagueness in Description Logics for the Semantic Web. Journal of Web Semantics, 6(4):291-308, 2008.

T. C. G. Mayor and R. Mesiar, editors. Aggregation operators: new trends and applications, volume 97. Physica-Verlag, Heidelberg, 2002.

G. Metcalfe and F. Montagna. Substructural fuzzy logics. Journal of Symbolic Logic, 72(3):834-864, 2007.

P. Mostert and A. Shields. On the structure of semigroups on a compact manyfold with boundary. Annals of Mathematics, 65:117-143, 1957.

J. Recasens. Indistinguishability Operators - Modelling Fuzzy Equalities and Fuzzy Equivalence Relations, volume 260 of Studies in Fuzziness and Soft Computing. Springer, 2011.

E. H. Ruspini. On the semantics of fuzzy logics. International Journal of Approximate Reasoning, 5:45-88, 1991.

R. Schalock and M. Verdugo. Handbook on quality of life for human service practitioners. American Association of Mental Retardation. Washington, DC, US, 2002.

A. Tversky. Features of similarity. Psychological Review, 84(4):327-352, 1977. ISSN 19391471.

L. A. Zadeh. Similarity relations and fuzzy orderings. Information Sciences, 3:177200, 1971. 